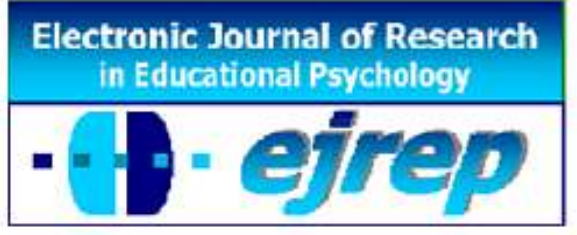

\title{
The Achievement Goal Questionnaire-Revised for Thai College Students and Asian Context
}

\author{
Ratsameemonthon L.
}

Didyasarin International College, Hatyai University, Hatyai, Songkhla, Thailand

\section{Thailand}

Correspondence: Ratsameemonthon L. Didyasarin International College, Hatyai University, Thailand. e-mail: inter.hu@gmail.com

(C) Education \& Psychology I+D+i and Ilustre Colegio de Psicología de Andalucía Oriental (Spain) 


\begin{abstract}
Introduction. The four dimensions $(2 \times 2)$ of achievement goal are the latest versión of achievement goal questionnaire to explain reasons or purposes of individuals pursuing their goal. In Thailand the $2 \times 2$ framework of achievement goal questionnaire to examine a student's achievement goal in the Thai Language version may not have been sufficiently researched. Therefore, it is necessary to develop achievement goal in the Thai version to assess students' achievement goal in order to investigate how they utilize their achievement goal to achieve in their academic performance as well as to examine whether an achievement goal assessment developed from Western perspective could apply in Thai context.
\end{abstract}

Method. The Thai version of AGQ-R was administered to 988 students from three selected universities located in Songkhla province Thailand. Exploratory factor analysis (EFA) was used to explain a common relationship of each variable, whereas, CFA was used to confirm the factor structure identified via EFA.

Results. The result of exploratory factor analysis (EFA) and confirmatory factor analysis (CFA) confirmed the four-factor structure of the Thai version of AGQ-R appeared to be the same as that of the original scale. The translated Thai version of AGQ-R demonstrated acceptable reliability and validity.

Discussion and conclusion. Theoretical perspective advocated a separation of the four-factor structure of achievement goal and could bridge the cultural gap of people living in different cultures having the same factor structural domain of achievement goal. Future research should be replicated with other academic years or with other educational levels or other locations to increase validity and reliability of this assessment.

Keywords: translation, validation, achievement goal, achievement goal questionnaire, college students. 


\title{
El Achievement Goal Questionnaire-Revised (AGQ-R) para estudiantes universitarios tailandeses $y$ el contexto asiático
}

\begin{abstract}
Resumen
Introducción. Las cuatro dimensiones $(2 \times 2)$ de metas de logro son la última versión del AGQ-R para explicar las razones o propósitos para alcanzar sus objetivos individuales. En Tailandia el marco 2x2 del AGQ-R no ha sido suficientemente investigado. Por consiguiente, es necesario desarrollar una versión tailandesa del AGQ-R para valorar las metas de logro de los alumnos con el fin de investigar como utilizan sus metas de logro para alcanzar sus objetivos académicos y a su vez evaluar si las metas de logro desarrolladas desde una perspectiva occidental se podría aplicar en un contexto tailandés.
\end{abstract}

Método. La versión tailandesa del AGQ-R fue administrada a 988 estudiantes de 3 universidades situadas en la provincial de Songkhla, Tailandia. El análisis factorial exploratorio (EFA) fue usado para explicar la relación común de cada variable, mientras el análisis factorial confirmatorio (CFA) fue usado para confirmar los factores estructurados identificados mediante EFA.

Resultados. Los resultados del análisis factorial exploratorio (EFA) y la confirmación del factor análisis (CFA) corroboraron los 4 factores de la versión tailandesa del AGQ-R demostraron ser la misma que en la escala original. La traducción a la versión tailandesa del AGQ-R demostró una aceptable veracidad y validez.

Discusión y conclusión. La perspectiva teórica aboga a la separación de las estructura 4factores del AGQ-R y podría superar las diferencias culturales de personas viviendo en diferentes culturas teniendo el mismo factor estructural propiedad del AGQ-R. Para investigaciones futuras se debería reproducir en otro año académico o con otro nivel educativo u otras localidades para aumentar la validez y veracidad de esta valoración.

Palabras clave: traducción, validación, metas de logro, cuestionario de metas de logros, estudiantes universitarios. 


\section{Introduction}

Many researchers have been trying over the years to explain and predict people's behaviors and their aspirations to accomplish tasks in different situations. Some people face burdens with a sense of challenge and joy whereas other people engage difficult tasks with a sense of helplessness and anxiety. One of the most important psychological constructs that influence people to achieve success is achievement goal (Elliot, 1999).

Achievement goal proposed within the concepts of Social Cognitive Theory of Motivation (SCTM) is a view of human agency in which individuals are agents proactively engaged in their own development including a possession of self-belief to direct their performance (Bandura, 1986). Therefore, an achievement goal can perform as a motivational belief or reason for individuals to regulate their own behaviors in pursuing their goals (Elliot, 2005). The achievement goal construct was introduced in the late 1970s and early 1980s through the independent and collaborative work of Carol Ames, Marol Dweck, Mary Maehr, and John Nicholls (Elliot, 1999). However, Dweck and Nicholls were the two pioneers that many researchers often referred to because their conceptualizations influenced many current works (Elliot, 2005). At the beginning, achievement goal had been separated into two types: learning goal or mastery goal and performance goal. According to the two initiators' conception, Dweck and Nicholls, individuals espousing a mastery goal believe their intelligence is malleable and can be improved. Therefore, they utilize internal referencing of a successful outcome in a past situation to regulate their performance to achieve a goal. On the other hand, individuals espousing a performance goal believe their intelligence and performance are fixed. Consequently, they apply external reference by comparing performance with others to motivate themselves to complete their goal. However, mixed results have been continuously shown in the dimension of performance goal. As a result, Elliot and his colleagues (Elliot \& Harackiewicz, 1996; Elliot \& Church, 1997) proffered that performance goal needs to be separated into approach and avoidance domains because they could have both negative and positive consequences on achievement-relevant processes and outcomes (Elliot, 1999). The conceptual distinction of approach and avoidance as derived from classic achievement motivation theory refers to the psychological concept of human behavior that brings about the pursuit of pleasure and avoidance of pain (Aristippus, 430-360 B. C., as cited in Elliot, 1999). Later, the pursuit of pleasure and avoidance of pain was used to explain a motivation of human success 
under the term "need for achievement and the desire to avoid failure" in achievement motivation theory. To support this idea, Elliot and Harackiewicz (1996) and Elliot and Church (1997) confirmed a separation of achievement goal into three dimensions: mastery goal, performance-approach goal, and performance- avoidance goal. After distinguishing performance goals, Elliot (2005) proposed a 2x2 achievement goal framework which stipulates approachavoidance dimensions of mastery goal as well as of performance goal. Therefore, a mastery goal in the form of avoidance was presented.

Moreover, an achievement goal could motivate students by utilizing reasons or purposes to achieve academic goals (Elliot \& Church, 1997). According to Elliot (2005), mastery-approach goal refers to "the development of competence or the attainment of task mastery" (p. 61). Individuals adopting mastery-approach goal strive to develop their skills and abilities, advance their learning, understand material, or master a task in order to support an intensive search for information to acquire much deeper knowledge (Elliot \& Church, 1997). As a result, it appears to be more positively related to task involvement and intrinsic motivation than merely the academic grade (Elliot \& Harackiewicz, 1996; Elliot \& Church, 1997; Elliot \& Murayama, 2008). Furthermore, Elliot (2005) introduced the concept of masteryavoidance goal to distinguish some cognitive avoidance within a mastery-approach goal. A mastery-avoidance goal is described as a focus on avoiding self-referential or task-referential incompetence. An individual with a mastery-avoidance goal strives to avoid losing one's skills and abilities. Therefore, a mastery-avoidance goal may relate to maladaptive learning styles and negative self-motivational beliefs because individuals employing masteryavoidance in their goals are only concerned with not being incorrect; therefore, they may be less able to apply adaptive help-seeking and instead tend towards more dependant helpseeking (Pintrich, 2000).

A performance goal also consists of two approach-avoidance dimensions. Individuals endorsing a performance goal perceive intelligence as fixed-an innate ability-and fear of others' negative judgment undergirds a performance goal. Fear of failure is activated in both dimensions of a performance goal, but they express fear of failure differently. Individuals espousing a performance-approach goal express fear of failure to augment their ability to achieve positive recognition by others in order to protect self-worth; therefore, fear of failure is described as a drive for students espousing a performance-approach goal to make more effort in pursuing a high score. In contrast, individuals adopting a performance-avoidance goal 
convey their fear of failure from others' judgment by escaping failure and avoid doing or postponing the completion of tasks. As a result, performance-avoidance goals are reported to be more highly associated with low academic performance and procrastination (Elliot \& Church, 1997; Wolters, 2004).

According to the above information, all of the four dimensions $(2 \times 2)$ of achievement goal associated with academic achievement function differently depending on reasons or purposes of individuals pursuing their goal. It may imply that assessing a student's achievement goal may enlighten us to understand reasons or purposes of students pursuing their academic goals. However, currently in Thailand the $2 \times 2$ framework of achievement goal questionnaire to examine a student's achievement goal in the Thai Language version may not have been sufficiently researched. It has only an instrument measuring teachers' achievement goals studied by Putharaksa, (2008). The achievement goal for teachers in the Thai version used the translation method and tested the qualities of evaluation tools in terms of validity and reliability with 768 teachers in schools under the Department of Education, Bangkok metropolis. The results found that the value of content validity, reliability, and construct validity reported within an acceptable range.

\section{Significance of study}

Utilizing previously developed instruments with accurate psychometric properties can save time and effort (Cha, Kim, \& Erlen, 2007). However, almost all of the instruments were developed from a Western perspective. Therefore, before investigating Western-developed instruments, it is necessary to obtain a valid translated instrument in order to have content in the other language which is equivalent to the original version as well as being relevant to the participants' language and culture. From the Eastern perspective, it has been reported that students' learning strategies differ from Western students' strategies which may be derived from many sources. For example, previous studies (e.g. Thongnoum, 2002) found that Thai students reported using a surface-learning process rather than a deep-learning process because the Thai educational system encourages students to apply rote memorization more than the processes of creative and critical thinking (Kaewdang, 1999 cited in Thongnoum, 2002). Moreover, Bong (2008) found that Korean students applied a performance-oriented goal more than a mastery-oriented goal because the performance-approach goal showed a greater positive relationship with academic grade than the mastery-approach goal did. Asian students try their best to attain high-grade scores because educational success is linked to the importance 
of bringing honor to one's family in Asian cultures (Oyserman \& Sakamoto, 1997). This may imply that Asian students might endorse achievement goal in a way that is different from Western students as a consequence of differing educational systems and cultural values.

\section{Objective}

Taken together, therefore, it is necessary to develop achievement goal in the Thai version to assess students' achievement goal in order to investigate how they utilize their achievement goal to achieve in their academic performance as well as to examine whether an achievement goal assessment developed from Western perspective could apply in Thai context.

\section{Method}

\section{Participants}

Participants were 988 undergraduate students who enrolled in three universities located in Songkhla province, Thailand which were chosen in order to obtain a representation of different types (public/private) and sizes (large/medium/small) of universities in the area. Their mean age was $20(\mathrm{SD}=0.99)$ years, ranging from 18 to 27 years and their GPA mean was 2.68 ( $\mathrm{SD}=0.57$ ), ranging from 1.08 to 4.00 . About $76 \%$ were female and $24 \%$ were male. They completed questionnaires voluntarily. Most of them were studying in the Business Administration department $(n=389)$ and in the Science department $(n=162)$.

\section{Instrumentation}

Achievement Goal Questionnaire-Revised (AGQ-R; developed by Elliot and Murayama, 2008). The revised version of AGQ-R was developed to rectify problems present in the original version of the Achievement Goal Questionnaire (AGQ developed by Elliot and McGregor 2001). For example, more direct and precise words were needed because achievement goals focus on purpose and guide future behaviors. Some of the original version items seem referenced to a minor group (e.g., some performance-based goal items focus on an extreme group) and some achievement-goal items may not compare equally with the normative group. AGQ-R consisted of 12 items which were separated equally and systematically organized into four achievement goals (mastery approach/avoidance goals, performance approach/avoidance goals). The mastery-approach goals focus on attaining task-based or intrapersonal competence (3 items). Mastery-avoidance goals involve avoiding task-based or intrapersonal incompetence (3 items). Performance-approach goals are based on attaining 
normative competence ( 3 items). And, performance-avoidance goals derive from avoiding normative incompectence ( 3 items). Participants responded on a scale of $1=$ absolutely disagree to $5=$ absolutely agree. All of the subscales demonstrated high levels of internal consistency. Regarding to the study of Elliot \& Murayama, 2008 conducted a study that examined the measure's structural validity and predictive utility of achievement goal questionnairerevised with 229 undergraduates at northeastern university in United States. The result showed that mastery-approach goals, mastery-avoidance goals, performance-approach goals, and performance-avoidance goals represented Cronbach's alphas equal to .84, .88, .92, and .94 , respectively (Elliot \& Murayama, 2008).

\section{Procedures}

To translate the AGQ-R into Thai, diverse methods were used to ensure that content, semantic, and technical equivalence was ascertained and was relevant to the target culture. To accomplish this, the achievement goal questionnaire was translated and back-translated by two independent bilingual experts. The first translator was granted a scholarship from the government to study abroad for one year. Moreover, she has performed non-full-time translation for more than five years, mostly related to academic contexts. The other translator also was granted the Royal Thai Government's Scholarship to study in the Graduate School of Arts \& Sciences, major Econometrics, at New York University in The United States for two years. Upon graduation, she has worked as a 'Plan and Policy Analyst' at the Bureau of International Industrial Economics, Office of Industrial Economics, Ministry of Industry for seven years. After, back and forth translation, the researcher compared and resolved discrepancies by discussing in committee (researcher and the two bilinguals). The discussion was aimed to convey items content 'equivalent to original version' as well as to be able to communicate as simply as in the Thai language. As a result, the committee made the necessary adjustments to the original version to rectify translation differences in order to obtain the final English original and the final Thai version. After receiving the final English and Thai versions, they were tested again on the other two independent bilingual experts. The second comparison supported the proposition that the modified English and back-translated versions were similar to each other. The final Thai version was then examined further during the 2011 academic year (November 2011 to May 2012), using direct contact to obtain 1,071 respondents. Only complete questionnaire were accepted; therefore, some questionnaires were took out (e.g., gave only straight line answer). Consequently, 988 completed questionnaires were deemed valid and subjected to data analysis. Prior to actual participation, the participants 
were fully notified about the purpose of the study via an informed consent form, and that was to be kept strictly confidential.

\section{Data Analysis}

Data derived from the 988 participants were divided into two groups: 494 were tested via exploratory factor analysis (EFA) and the other 494 were assessed through confirmatory factor analysis (CFA). EFA was used to explain a common relationship of each variable to determine whether two or more could be combined into the same variable if they demonstrate a high correlation and share some common characteristics, whereas, CFA was used to confirm the factor structure identified via EFA. A goodness-of-fit model with the empirical data was indicated by the incremental fit indices (Normed Fit Index - NFI, Incremental Fit Index - IFI, Tucker-Lewis Index - TLI, Comparative Fit Index - CFI) is close to or at 1 (a perfect fit) and Root Mean Square Error of Approximation (RMSEA) ranged from .05 to .08 are acceptable values suggested by Browne and Cudeck (1993). Cronbach's alphas were then used to identify the internal consistency (reliability) of the scales indicated 0.7 to be an acceptable reliability coefficient (Nuunaly, 1978).

\section{Results}

The result showed that data's distribution of the four factors of achievement goal is admissible regarding assumption that the areas present under the normal curve. Table 1 demonstrates means, standard deviations, minimum-maximum, Cronbach's alpha coefficients, and Item-total correlation. Table 2 and Figure 1 show summary of factor loading of achievement goal questionnaire-revised.

Table 1. Means, Standard Deviations, Min-Max, Reliabilities, and Item-total Correlation $(\mathbf{N}=988)$

\begin{tabular}{lccccc}
\hline & $M$ & SD & Min-Max & Reliability & $\begin{array}{c}\text { Item-total } \\
\text { Correlation }\end{array}$ \\
\hline Mastery-approach goals & 3.97 & 0.63 & $1.00-5.00$ & 0.72 & $.52-.57$ \\
Mastery-approach goals & 3.41 & 0.77 & $1.00-5.00$ & 0.62 & $.32-.52$ \\
Performance-approach goals & 3.65 & 0.89 & $1.00-5.00$ & 0.65 & $.43-.51$ \\
Performance-avoidance goals & 3.57 & 0.75 & $1.00-5.00$ & 0.70 & $.48-.54$ \\
\hline
\end{tabular}




\section{Exploratory Factor Analysis}

The initial unrotated to principal components analysis (PCA) resulted in a factor model of four dimensions as indicated by the screen plot and eigenvalues exceeding unity. However, based on its pattern of factor loading, this unrotated factor model was theoretically less meaningful and was difficult to interpret. Therefore, the analysis proceeded to rotate the factor matrix orthogonally by varimax rotation to achieve a simple and theoretically more meaningful solution. Since, this research aims to identify whether achievement goal questionnairerevised could assess Thai students' achievement goal and proposed that each of the goal achievement dimension represents a distinct construct; therefore, varimax rotation was applied because this rotation technique aims at maximizing the sum of variances of squared loadings in the columns of the factor matrix (Kline, 1994). From the rotated matrix, 12 items were retained, using the criteria of selecting items with factor structure coefficients greater than or equal to .33 and no significant cross-loadings. The use of the .33 value is based on the logic that squaring the correlation coefficient $\left(.33^{2}\right)$ yields approximately $10 \%$ of the variance explained and had eigen-values greater than 1.00. All items loaded .75 and above on their primary factor; none of the secondary loading exceeded .35. Together the four factors accounted for $61.8 \%$ of the total variance.

Table 2. Summary of Factor Loading by Principal Components Analysis for the Orthogonal Four-Factor Model of Achievement Goal Questionnaire-Revised

\begin{tabular}{|c|c|c|c|c|}
\hline \multirow[t]{2}{*}{ Item } & \multicolumn{4}{|c|}{ Factor loading } \\
\hline & 1 & 2 & 3 & 4 \\
\hline My goal is to learn as much as I can. & .82 & & & \\
\hline $\begin{array}{l}\text { My goal is to fully understand the contents thought in } \\
\text { class. }\end{array}$ & .79 & & & \\
\hline $\begin{array}{l}\text { I try very hard to understand as deep as possible in this } \\
\text { subject matter. }\end{array}$ & .74 & & & \\
\hline $\begin{array}{l}\text { My goal is to avoid producing worse work than other stu- } \\
\text { dents. }\end{array}$ & & .82 & & \\
\hline I try hard to avoid producing worse work than others. & & .81 & & \\
\hline $\begin{array}{l}\text { My goal is to avoid having bad work when compared to } \\
\text { other students. }\end{array}$ & & .69 & & \\
\hline $\begin{array}{l}\text { My goal is to behave well when compared to other stu- } \\
\text { dents. }\end{array}$ & & & 78 & \\
\hline $\begin{array}{l}\text { I am determined to do well when compared to other stu- } \\
\text { dents. }\end{array}$ & & & 75 & \\
\hline My goal is to produce a better work than other students. & & & 72 & \\
\hline My goal is to avoid learning less than my capability. & & & & 85 \\
\hline My goal is to avoid learning less than what it should be. & & & & 81 \\
\hline I try to avoid partially understanding of the subject. & & & & 51 \\
\hline $\begin{array}{l}\text { Factor } 1 \text { = Mastery-approach goal; } \\
\text { Factor } 3 \text { = Performance-approach goal; }\end{array}$ & $-a$ & & & \\
\hline
\end{tabular}




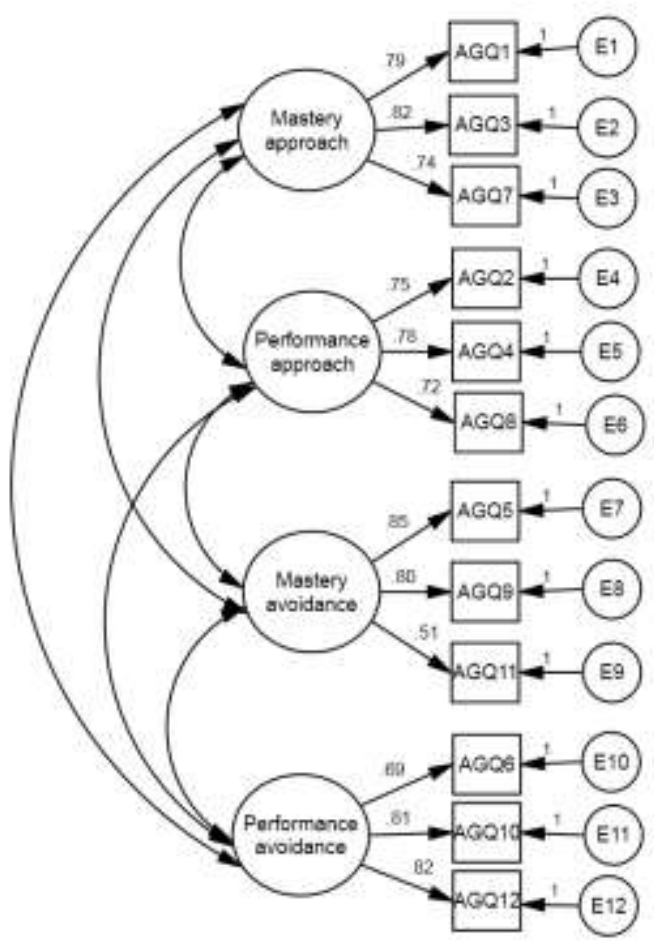

Figure1. Confirmatory factorial analysis of the four-factor measurement model representing achievement goal.

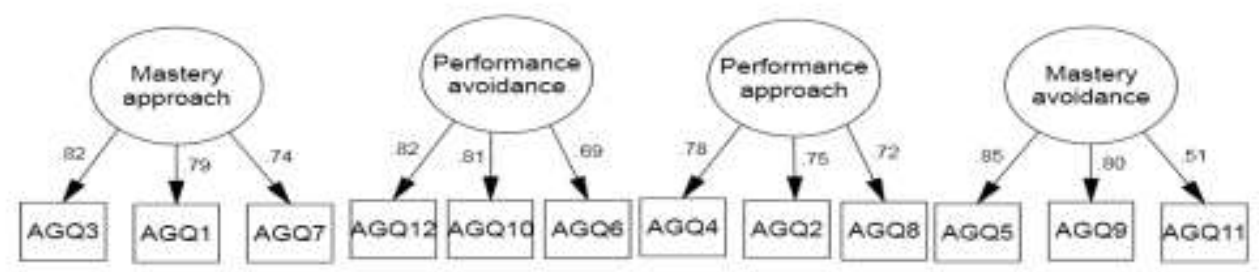

Figure2. Factor loading of the four-factor measurement model representing achievement goal

The first factor accounted for $24.68 \%$ of the variance (eigenvalue $=2.96$ ) and consisted of three mastery-approach goal items. The second factor accounted for $16.04 \%$ of the variance (eigenvalue $=1.92$ ) and consisted of three performance-avoidance goal items. The third factor accounted for $11.09 \%$ of the variance (eigenvalue $=1.33$ ) and consisted of three performance-approach goal items. The fourth factor accounted for $9.99 \%$ of the variance (eigenvalue $=1.19)$ and consisted of three mastery-avoidance goal items. The result from ex- 
ploratory factor analysis reported that the factor structure of the Thai version of AGQ-R appeared to be the same as that of the original scale.

\section{Confirmation Factor Analysis (CFA)}

CFA was employed to test the null hypothesis that the sample covariance matrix was obtained from a population that has the proposed model structure. Table 3 presents the goodness-of-fit indices for this model. Table 4 and Figure 2 demonstrate standardized regression weights of the four-factor measurement model representing achievement goal.

Table 3. $\chi^{2}$ Goodness-of-Fit Value, Normed Fit Index (NFI), Incremental Fit Index (IFI), TuckerLewis Index (TLI), Comparative Fit Index (CFI), and Root Mean Square Error of Approximation (RMSEA) of Achievement Goal

\begin{tabular}{lcccccccc}
\hline Model & $\chi^{2}(N=494)$ & $d f$ & $p$ & NFI & IFI & TLI & CFI & RMSEA \\
\hline Four-factor & 138.68 & 48 & $<.001$ & 0.89 & 0.93 & 0.90 & 0.92 & 0.06 \\
Model of & & & & & & & & \\
Achievement goc & & & & & & & & \\
\hline
\end{tabular}

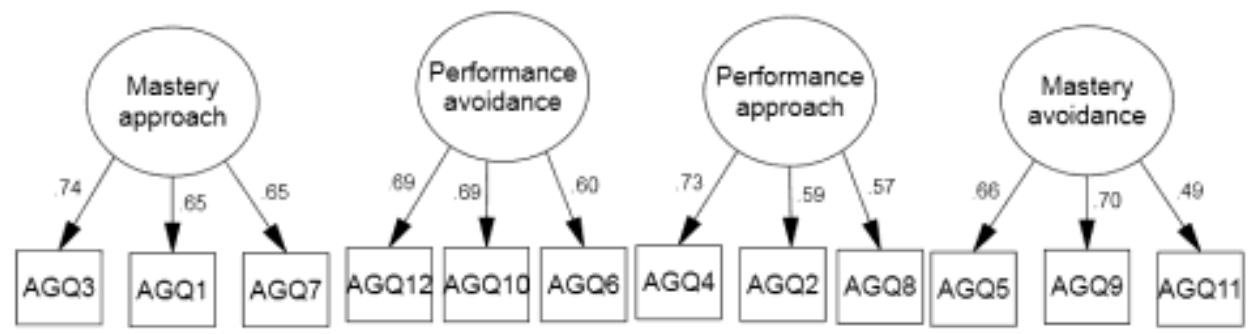

Figure 3. Standardized Regression Weights of the four-factor measurement model representing achievement goal 


\begin{tabular}{lllll}
\hline Item & Estimate & S.E. C.R. & Standardized \\
& & & $\begin{array}{c}\text { Regression } \\
\text { Weights }\end{array}$ \\
\hline
\end{tabular}

Mastery-Approach Goal

My goal is to fully understand the contents taught in class.

My goal is to learn as much as I can.

$\begin{array}{lllll}1.00 \quad- & - & - & .66\end{array}$

I try very hard to understand as deep as possible in this subject matter.

$\begin{array}{lllll}1.21 & .117 & 10.34 & <.001 & .76\end{array}$

$\begin{array}{lllll}.94 & .094 & 9.93 \quad<.001 \quad 60\end{array}$

\section{Performance-Approach Goal}

I am determined to do well when compared to other students.

My goal is to behave well when compared to other students.

$\begin{array}{lllll}1.29 & .140 \quad 9.22 \quad<.001 \quad .76\end{array}$

My goal is to produce a better work than other students.

$\begin{array}{lllll}1.08 & .123 & 8.77 \quad<.001 & .56\end{array}$

\section{Mastery-Avoidance Goal}

My goal is to avoid learning less than my capability.

$-$

My goal is to avoid learning less than what it should be.

$\begin{array}{lllll}.82 & .091 & 8.98 & <.001 & .65 \\ .76 & .088 & 8.68 & <.001 & .57\end{array}$

I try to avoid partially understanding of the subject.

\section{Performance-Avoidance Goal}

My goal is to avoid having bad work when compared to other students.

I try hard to avoid producing worse work than others.

Results indicated that the model fitted the data well. Although the overall chi-square value was significant, $\chi 2(\mathrm{df}=48)=138.68, p<.001$, the incremental fit indices (NFI, IFI, TLI, and CFI) were close to or above .90 (range: .89 to .93 ). These fit indices indicated that the model provided a good fit relative to a null or independent model. The RMSEA value of .06 
is also within the range (.04 to .08) suggested by Browne and Cudeck (1993) and 90\% CI = $.05-.74$ indicate that the model fits the population covariance matrix reasonably well. The standardized regression coefficients (factor loadings) for the measurement indicators were all positive and significant by the critical ratio test, (C.R. $>+1.96, \mathrm{p}<.001)$. Standardized loadings ranged from .56 to $.76(\mathrm{M}=.64)$. These values suggested that the indicator variables hypothesized to represent their respective latent constructs did so in a reliable manner. The percentage of residual (unexplained) variance for the 12 indicator variables ranged from $42 \%$ to $69 \%$.

\section{Discussion}

The result confirmed that the examination of the domain of achievement goal in two different cultures (Western and Eastern perspectives) represented the same four domains of achievement goal. Similar to Awofala, Arigbabu, Fatade and Awofala, (2013) studied the validity of $2 \times 2$ framework of achievement goal within the context of African students in Nigeria living in collectivist society. They also found a four-factor model of achievement goal fitted in the Nigeria's student with high alpha values. The four factorial structures of the Thai AGQ-R distinctly supported the four factorial structures of the original English AGQ-R, which was developed by Elliot and McGregor (2001), and Elliot and Murayama (2008). The four-factor structure of achievement goal has been grounded in established theories and philosophies such as the theories of intelligence which illustrate the reasons for individuals adopting mastery and performance goals. For example, the intelligence theory stated that individuals adopting an incremental theory who believe that intelligence is malleable and can be improved through increasing effort were likely to espouse mastery goals. In contrast, individuals adopting an entity theory who believe that intelligence and performance are fixed as an innate ability were likely to espouse performance goals (Elliot, 1999). Moreover, the hedonism of human needs for achievement motivation verified a separation of the approach (need for success) and avoidance (fear of failure) domains. This strong theoretical perspective advocated a separation of the four-factor structure of achievement goal and could bridge the cultural gap of people living in different cultures having the same factor structural domain of achievement goal.

It is quite interesting that why Thai students also adopt Mastery approach goal even if students' in Asian context are more likely to endorse performance goal than mastery goal 
(Bong, 2008; Thongnoum, 2002). Due to that fact that, individuals from Southeast Asia may often pursue others' goals, particularly those of their parents as their own goals, in order to maintain harmony between the self and parents as a given family's obligation (Pomerantz, Grolnick, \& Price, 2005). In the research of Meece, Blumenfeld, and Hoyle (1988) and Bong (2008) found significant others could play a role in influencing students to adopt mastery goal as well. They found that when students believe their teachers are emphasizing mastery of the learning tasks and that a deep understanding of the study material is more important than test scores, the students are more likely to adopt the mastery goal than to endorse the performance goal. Gonida, Karabenick, Makara and Hatzikyriakou (2014) found that perceived parent's acheivement goals could predict their children seeking help and help avoidance attitude as well as achievement goals. It could be implied that although the mastery goal focuses on selfimprovement, it may be used less by Asian students because they are less motivated by success and more motivated by avoidance of failure (Chiu \& Hong, 2005). As a result, the working out of the role of significant others toward students may influence Thai students to adopt the mastery-approach goal to pursue their academic goals in this research.

Although, in this research verified that the four domains of achievement goal from the Western perspective could be applied in Thai context, the reliability estimates for the scores on the Thai achievement goal questionnaire-revised ( $\alpha$ ranged from .62 to .72) found in this study were lower than those reported by Elliot \& Murayama, (2008) for the original version of the scales ( $\alpha$ ranged from .84 to .94 ). The possible explanation was that the items of these scales were based on theory and research developed in the United States and published in English language journals. Even though the translation of the items into Thai was verified by bilingual experts and that the translated items were subjected to a content validation process, some of the items might not have been clear, causing students to misinterpret the items and respond on some basis unrelated to the content being measured, thereby lowering the reliability of the responses. Moreover, Elliot \& Murayama, (2008) mentioned about the combination of positive and negative contents particular in mastery avoidance goal which may create a puzzling interpretation how this achievement goal operates.

\section{Limitations of the study and Future research}

The limitations should be noted and interpretation should be cautious on the present findings. First, since this research examined sophomore students studying in the universities located in Songkhla province, generalization of results to other Thai undergraduate students is 
limited. Future research should be replicated with other academic years or with other educational levels or other locations to increase validity and reliability of this assessment. Second, the two factors of achievement goals assessed in the current study showed low Cronbach's alphas for performance-approach and mastery-avoidance; therefore, achievement goal in the Thai version should be replicated to verify and validate the instrument' reliability.

\section{Implication}

Identifying a student's specific achievement goal may be utilized as guidance for teachers, school counselors, and psychologists to assist students to achieve academic performance more effectively. Specially, Eastern students may often pursue others' goals and strive for success to please significant others in order to maintain harmony between the self and parents as a given family obligation (Pomerantz, Grolnick, \& Price 2005). Consequently, students with performance goal who are highly concerned and stressed about demonstrating and proving competence will be more worried and anxious when they face more threatening and challenging goals. Consequently, they will tend to use maladaptive coping strategies such as selfhandicapping or procrastination to protect their self-worth (Wolters, 2004). At the same time, students who adopt performance-avoidance goal may cheat to achieve a high grade in order to fulfill their obligation to their parents (Bong, 2008). Therefore, teachers, school counselors, and psychologists could facilitate students holding a performance oriented goal to realize the negative consequences of fear of failure as well as to enhance students' self-efficacy to focus on process orientation rather than outcome orientation. This will assist student to be more flexible and to have self-reliance to deal with the challenging tasks and the unexpected negative consequences (Elliot, 2005).

\section{Conclusions}

Currently, in Thailand, assessment measure of achievement goal based on $2 \times 2$ dimensions in the Thai version is necessary to acquire further research due to different cultural perspective leads to adopt achievement goal differently. Therefore, the purpose of this research is to translate and establish a valid achievement goal in the Thai version in order to convey items' content equivalent to the original version and also to examine a specific achievement goal for Thai students. The results of EFA and CFA computations confirmed the four-factor structure of Thai version to be similar to the four-factor structure of the original Western version of the 
achievement goal questionnaire. The strong theoretical perspective and the role of significant others could explain the two versions' (Thai vs. Western) of achievement goal representing the same four-factor structure.

\section{Acknowledgements}

I am deeply appreciative of Assoc.Prof. Dr. Arunya Tuicomepee who devoted her valuable time to advise regarding this article.

\section{References}

Awofala, A. O. A., Arigbabu, A. A., Fatade, A. O., \& Awofala, A. A. (2013). Examining the psychometric properties of the achievement goals questionnaire among Nigerian preservice mathematics and science teachers. Electronic Journal of Research in Educational Psychology, 11(3), 743-770. doi:10.14204/ejrep.31.13037.

Bandura, A. (1986). Social foundations of thought and action: A social cognitive theory.Englewood Cliffs, NJ: Prentice Hall.

Bong, M. (2008). Effect of parent-child relationships and classroom goal structures on motivation, help-seeking avoidance, and cheating. The Journal of Experimental Education, 76, 191-217.

Browne, M. W., \& Cudeck, R. (1993). Alternative ways of assessing model fit. In K. A. Bollen \& J. S. Long (Eds.), Testing structural equation models (pp. 445-455). Newbury Park, CA: Sage.

Cha, Chiu, C.Y., \& Hong, Y.Y. (2005). Cultural Competence. In A. J. Elliot \& C. Carol (Eds.), Handbook of competence and motivation (pp.489-505). New York: Guilford Press.

De la Fuente, J. (2004). Recent perspectives in the study of motivation: Goal Orientation Theory. Electronic Journal of Research in Educational Psychology, 2(1), 35-62.

Elliot, A. J. (1999). Approach and avoidance motivation and achievement goals. Educational Psychologist, 34, 169-189. doi: 10.1207/s15326985ep3403_3

Elliot, A. J. (2005). A conceptual history of the achievement goal construct. In J. A. Elliot \& C. Carol (Eds.), foreword by C.V. Martin, Handbook of competence and motivation (pp. 5272). NewYork: Guilford Press.

Elliot, A. J., \& Church, M. A. (1997). A hierarchical model of approach and avoidance achievement motivation. Journal of Personality and Social Psychology, 72, 218-232. doi:10.1037/002-3514.72.1.218. 
Elliot, A. J., \& Harackiewicz, J. (1996). Approach and avoidance achievement goals and intrinsic motivation: A mediational analysis. Journal of Personality and Social Psychology, 70, 461-475. doi:10.1037/0022-3514.70.3.461.

Elliot, A. J., \& McGregor, H. A. (2001). A 2 x 2 achievement goal framework. Journal of Personality and Social Psychology, 80, 501-519. doi:10.1037/0022-3514.80.3.501.

Elliot, A. J., \& Murayama, K. (2008). On the measurement of achievement goals: Critique, illustration, and application. Journal of Educational Psychology, 100, 613-628. doi: 10.1037/0022-0663.100.3.613.

Gonida, E. N., Karabenick, S. A., Makara, K. A., \& Hatzikyriakou, G. A. (2014). Perceived parent goals and student goal orientations as predictors of seeking or not seeking help: does age matter? Learning and Instruction, 33, 120-130. doi:10.1016/j.learninstruc.2014.04.007.

Kline, P. (1994). An easy guide to factor analysis. London: Routledge.

Meece, J.L., Blumenfeld, P.C., \& Hoyle, R.H. (1988). Students' Goal Orientation and Cognitive engagement in classroom activities. Journal of Educational Psychology. 80, 514-523. doi: 10.1037/0022-0663.80.4.514.

Nunnaly, J. (1978). Psychometric theory. New York: McGraw-Hill.

Oyserman, D., \& Sakamoto (1997). Being Asian American: Identity, cultural constructs, and stereotype perception. The Journal of Applied Behavioral Science, 33, 435-453. doi: $10.1177 / 0021886397334002$.

Pintrich, P. R. (2000). The role of goal orientation in self-regulated learning. In M. Boekaerts, P. R. Pintrich, \& M. Zeidner (Eds.) Handbook of self-regulation (pp.451-502). San Diego, CA: Academic Press.

Pomerantz, M. E., Grolnick, S. W., \& Price, E. C. (2005). The role of parents in how children approach achievement: A dynamic process perspective. In A. J. Elliot \& C. Carol (Eds.), Handbook of competence and motivation (pp.259-278). NewYork: Guilford Press.

Putharaksa, C. (2008). Development of evaluation tools for teachers' achievement goals in school. (Unpublished master's thesis). Chulalongkorn University, Bangkok, Thailand.

Thongnoum, D. (2002). Self-efficacy, goal orientation, and self-regulated learning in Thai students (Unpublished doctoral dissertation). Oklahoma State University, United States.

Wolters, C. A. (2004). Advancing achievement goal theory: Using goal structures and goal orientations to predict students' motivation, cognition, and achievement. Journal of Educational Psychology, 96, 236-250. doi: 10.1037/0022-0663.96.2.236. 